\title{
Imidazole Catalyses in Aqueous Systems. $X$. Enzyme-like Catalytic Hydrolyses of Phenyl Esters by Polymers Containing Imidazole and Other Anionic Functions*
}

\author{
Seiji ShinkaI and Toyoki Kunitake** \\ Department of Organic Synthesis, Faculty of Engineering, \\ Kyushu University, Fukuoka 812, Japan.
}

(Received November 18, 1974)

\begin{abstract}
The catalytic hydrolysis of $p$-acetoxybenzoic acid (ABA-) and 3-acetoxy$N$-trimethylanilinium iodide $\left(\mathrm{ANTI}^{+}\right)$was carried out mainly at $30^{\circ} \mathrm{C}$ and $\mathrm{pH} 8.0$ in $1.0-M$ aqueous $\mathrm{KCl}$. The polymer catalysts used were water-soluble terpolymers of acrylamide, $N$-[ $p$-(4(5)-imidazolyl)benzyl]acrylamide (PI unit), and $N$-phenyl-methacrylamide derivatives with anionic functional groups such as sulfonate (BS unit), carboxylate (BA unit), hydroxyl (NP unit), and hydroxamate groups (HA unit). Michaelis-Menten kinetics were observed for all the catalysts; the reaction constants were $K_{\mathrm{m}}=14.5-200$ $\mathrm{m} M$ and $k_{\mathrm{cat}}=0.004-0.026 \mathrm{~min}^{-1}$ for the imidazole catalysis. The $K_{\mathrm{m}}$ value for $\mathrm{ANTI}^{+}$ decreases with increase in the content of BS and BA units in the polymers. On the other hand, the value of $K_{\mathrm{m}}$ for $\mathrm{ABA}^{-}$triples during the same increase: this establishes that the electrostatic interaction contributes to the substrate binding in addition to the hydrophobic interaction. The plot of $k_{\text {cat }} v s$. the BA content in the PI-BA polymers gave a maximum at $c a .30-\mathrm{mol} \% \mathrm{BA}$ unit, whereas the $k_{\text {cat }}$ value for $\mathrm{PI}-\mathrm{BS}$ polymer increased monotonously. These trends suggest the existence of cooperative action between the imidazole and carboxylate functions, but not between imidazole and sulfonate. The plots of $\log k_{\text {cat }} v s . \mathrm{p} K_{\text {a }}$ of the anionic functional groups gave good linear relationships, and the general-basic contribution of the anionic functional groups is proposed. The catalytic behavior of the PI-HA polymer features the burst alkali consumption due to the HA unit. A novel scheme involving the acyl transfer from HA unit to PI unit, which is a model of $\alpha$-chymotripsin, is suggested.
\end{abstract}

KEY WORDS Polymer Catalyst / Imidazole / Hydrolysis / MichaelisMenten Kinetics / Multifunctional Catalysis /

Previously we showed that some water-soluble copolymers containing the imidazole unit catalyzed the hydrolysis of phenyl esters according to Michaelis-Menten kinetics: ${ }^{1-6}$

$$
\mathrm{C}+\mathrm{S} \underset{K_{\mathrm{m}}}{\underset{\mathrm{C}}{\longrightarrow}} \mathrm{C} \cdot \mathrm{S} \stackrel{k_{\mathrm{cat}}}{\longrightarrow} \mathrm{C}+\mathrm{P}
$$

where $\mathrm{C}, \mathrm{S}$, and $\mathbf{P}$ denote catalyst (neutral imidazole), substrate, and product, respectively. The corresponding reaction rate is expressed by eq 2 , which indicates saturation of the reaction rate at high substrate concentrations.

* Contribution No. 344 from this department. Presented in part at the 20th Polymer Symposium, Tokyo, Nov., 1971.

** Correspondence should be addressed to this author.

$$
v_{\text {cat }}=\frac{k_{\mathrm{cat}}[\mathrm{C}][\mathrm{S}]}{K_{\mathrm{m}}+[\mathrm{S}]}
$$

With these polymer catalysts, substrates were found to be bound to the catalytic sites of polymers by the hydrophobic force as well as by the electrostatic interaction, and the existence of the carboxylate group as a polymeric neighboring group enhanced the nucleophilic activity of the imidazole group in the hydrolysis of a cationic phenyl ester. ${ }^{5}$ These results encouraged us to design polymer catalysts in which an imidazole group is densely surrounded by several anionic functions.

It was found in the case of water-soluble copolymers of acrylamide with some hydrophobic monomers that the pendent hydrophobic groups 


\section{S. Shinkai and T. Kunitake}

aggregate to form a strengthened binding site. ${ }^{3}$ In order to improve the catalytic efficiency we intended to utilize the aggregated conformation through the introduction of imidazole and anionic functions at the tip of the hydrophobic pendent. If the aggregation of such functional groups is actualized, the polymer would possess a hydrophobic binding site and a multifunctional catalytic

Catalysts:<smiles>CCC(C)C(N)=O</smiles>

AAm unit<smiles></smiles>

PI unit
A:<smiles>Cc1ccc(S(=O)(=O)[O-])c(C(=O)c2ccc(C)c([N+](=O)[O-])c2)c1</smiles><smiles>COC(=O)N([O-])c1ccc(I)cc1</smiles>

HA unit

Substrates:<smiles>CC(=O)Oc1ccc(C(=O)[O-])cc1</smiles>

$\mathrm{ABA}^{-}$

\section{Materials}

Monomers and catalysts: $N$-[ $p$-(4(5)-imidazolyl) benzyl]acrylamide(PI monomer) and 4(5)-( $p$-acetamidomethylphenyl)-imidazole(AcPI) were obtained as described previously. ${ }^{3,4}$

Sodium $N$-(p-methacryloyl)-aminobenzenesulfonate(BS monomer) was prepared from an equimolar mixture of sodium $p$-aminobenzenesulfonate and methacryloyl chloride in an ice bath in the presence of excess sodium acetate. The aqueous solution was poured into acetone and the precipitates $(\mathrm{NaCl})$ were filtered. White site as in the active sites of some esterolytic enzymes. ${ }^{7}$ Thus, the following terpolymers were synthesized from the corresponding monomers, and their catalytic efficiencies for $\mathrm{ANTI}^{+}$and $\mathrm{ABA}^{-}$were assessed. Acrylamide was used as a component to keep the terpolymers watersoluble.<smiles>CCC(C)(C)C(=O)NC</smiles><smiles>CC(=O)Cc1ccc(-c2nnc[nH]2)cc1</smiles>

AcPI
A unit 
Ester Hydrolysis by Polymer Catalysts

Table I. Identification of monomers

\begin{tabular}{|c|c|c|c|c|c|c|c|c|c|c|c|c|}
\hline \multirow{3}{*}{ Monomer } & \multirow{3}{*}{$\underset{{ }^{\circ} \mathrm{C}}{\mathrm{mp}}$} & \multirow{3}{*}{$\underset{\%}{\text { Yield, }}$} & \multicolumn{3}{|c|}{ IR (KBr) } & \multicolumn{7}{|c|}{ E.A. } \\
\hline & & & \multirow{2}{*}{$\nu \mathrm{C}=0$} & \multirow{2}{*}{\multicolumn{2}{|c|}{$\begin{aligned} & \nu_{\mathrm{C}}=\mathrm{C} \\
& \mathrm{cm}^{-1}\end{aligned}$}} & \multicolumn{3}{|c|}{ Found } & \multicolumn{3}{|c|}{ Calcd } & \multirow[t]{2}{*}{ for } \\
\hline & & & & & & $\mathrm{C}$ & $\mathrm{H}$ & $\mathbf{N}$ & $\mathrm{C}$ & $\mathbf{H}$ & $\mathbf{N}$ & \\
\hline BS & - & 74 & 1656 & & 1620 & 45.41 & 3.81 & 5.88 & 45.62 & 3.83 & 5.32 & $\mathrm{C}_{10} \mathrm{H}_{10} \mathrm{NO}_{4} \mathrm{SNa}$ \\
\hline BA & $220-221^{a}$ & a 78 & 1690 & 1670 & 1624 & 63.41 & 5.48 & 6.77 & 63.48 & 5.40 & 6.38 & $\mathrm{C}_{11} \mathrm{H}_{11} \mathrm{NO}_{3}$ \\
\hline NP & $108-109$ & 66 & 1658 & & 1615 & 53.98 & 4.51 & 12.52 & 54.05 & 4.54 & 12.61 & $\mathrm{C}_{10} \mathrm{H}_{10} \mathrm{~N}_{2} \mathrm{O}_{4}$ \\
\hline $\mathrm{NPac}$ & $132-133$ & 82 & & & & 54.54 & 4.58 & 10.60 & 55.88 & 4.68 & 10.77 & $\mathrm{C}_{12} \mathrm{H}_{12} \mathrm{~N}_{2} \mathrm{O}_{5}$ \\
\hline $\begin{array}{l}N \text {-( } p \text {-nitrophenyl)- } \\
\text { methacrylamide }\end{array}$ & $143-144$ & 84 & 1670 & & 1612 & 58.22 & 4.66 & 13.51 & 58.25 & 4.89 & 13.59 & $\mathrm{C}_{10} \mathrm{H}_{10} \mathrm{~N}_{2} \mathrm{O}_{3}$ \\
\hline HAac & $\begin{array}{r}171-174^{\circ} \\
(\mathrm{dec}\end{array}$ & ec) & 1735 & 1670 & 1622 & 59.56 & 5.91 & 10.19 & 60.86 & 5.84 & 10.14 & $\mathrm{C}_{14} \mathrm{H}_{16} \mathrm{~N}_{2} \mathrm{O}_{4}$ \\
\hline
\end{tabular}

a lit $^{8} \mathrm{mp} 215-216^{\circ} \mathrm{C}$

b Yield based on $N$-( $p$-hydroxylaminophenyl)-methacrylamide.

Vigneaud. ${ }^{9} \quad N-(p$-nitrophenyl $)$-methacrylamide was reduced to $N$-( $p$-hydroxylaminophenyl)methacrylamide by $\mathrm{Zn}-\mathrm{HCl}$ in $\mathrm{NH}_{4} \mathrm{Cl}$-buffered aqueous THF solution, ${ }^{10} \mathrm{mp} 170-210^{\circ} \mathrm{C}(\mathrm{dec})$, yield $82 \%$. A broad absorption was observed at $3300-3000 \mathrm{~cm}^{-1}$ in the IR spectrum $(\mathrm{KBr})$. The hydoxylamine derivative was treated with acetic anhydride to provide $N$-( $p$-methacryloylamidophenyl)- $N, O$-diacetyl-hydroxylamine (HAac monomer). The yield of the product was low, but no further attempts were made to improve the yield. All analytical results are summarized in Table I.

Substrates: Preparations of $p$-acetoxybenzoic $\operatorname{acid}\left(\mathrm{ABA}^{-}\right)$and 3-acetoxy- $N$-trimethylanilinium iodide $\left(\mathrm{ANTI}^{+}\right)$were described previously. ${ }^{3,5}$

\section{Polymerization and Deacylation}

Polymerizations were conducted using azobisisobutyronitrile (AIBN) as initiator at $70^{\circ} \mathrm{C}$. The results are summarized in Table II. Watersoluble polymers were purified by reprecipitation from water to methanol. Some polymers were dissolved by neutralization with aqueous $\mathrm{NaOH}$ solution and reprecipitated from water to methanol-acetone $(1: 1)$.

Polymers containing the HAac monomer unit were dissolved in a diluted aqueous $\mathrm{NaOH}$ solution and left at room temperature overnight. The solutions were poured into acetone or methanol-acetone $(1: 1)$ and polymers containing $N$-( $p$-methacryloylamidophenyl)-acetohydroxamic acid(HA monomer unit) were obtained.

The composition of PI unit was always sup-
Table II. Polymerization ${ }^{\mathrm{a}}$

\begin{tabular}{|c|c|c|c|c|c|}
\hline \multirow{2}{*}{ Polymer } & \multicolumn{3}{|c|}{ Monomer feed, $M$} & \multirow{2}{*}{$\begin{array}{c}\text { Poly- } \\
\text { merization } \\
\text { time, min }\end{array}$} & \multirow{2}{*}{$\begin{array}{c}\text { Con- } \\
\text { version, } \\
\%\end{array}$} \\
\hline & $\mathrm{PI}$ & A & AAM & & \\
\hline \multicolumn{6}{|c|}{$\mathbf{A}=\mathbf{B S}^{\mathbf{b}}$} \\
\hline PI-BS-1 & 0.05 & 0.05 & 2.00 & 40 & 30.2 \\
\hline PI-BS-2 & 0.05 & 0.30 & 2.00 & 40 & 35.9 \\
\hline PI-BS-3 & 0.05 & 0.56 & 1.50 & 40 & 32.5 \\
\hline PI-BS-4 & 0.05 & 1.50 & 0.50 & 120 & 29.1 \\
\hline PI-BS-5 & 0.08 & 2.00 & 0 & 120 & 18.6 \\
\hline \multicolumn{6}{|c|}{$\mathrm{A}=\mathrm{BA}^{\mathrm{c}}$} \\
\hline PI-BA-1 & 0.05 & 0.05 & 2.00 & 60 & 38.1 \\
\hline $\mathrm{PI}-\mathrm{BA}-2$ & 0.05 & 0.30 & 2.00 & 60 & 46.5 \\
\hline $\mathrm{PI}-\mathrm{BA}-3$ & 0.05 & 0.50 & 1.50 & 40 & 32.1 \\
\hline $\mathrm{PI}-\mathrm{BA}-4$ & 0.05 & 1.00 & 1.00 & 120 & 32.0 \\
\hline PI-BA-5 & 0.05 & 2.00 & 0 & 120 & 22.5 \\
\hline \multicolumn{6}{|c|}{$\mathrm{A}=\mathrm{NP}^{\mathrm{d}}$} \\
\hline PI--NP-1 & 0.05 & 0.05 & 2.00 & 240 & 22.4 \\
\hline PI-NP-2 & 0.07 & 0.10 & 2.00 & 600 & 16.2 \\
\hline NP-1 & 0 & 0.05 & 2.00 & 240 & 18.5 \\
\hline \multicolumn{6}{|c|}{$\mathrm{A}=\mathrm{NPac}$} \\
\hline $\mathrm{PI}-\mathrm{NPac}$ & 0.03 & 0.10 & 1.00 & 180 & 25.1 \\
\hline NPac-1 & 0 & 0.10 & 1.00 & 180 & 30.0 \\
\hline \multicolumn{6}{|c|}{$\mathrm{A}=\mathrm{HAac}$} \\
\hline PI-HAac & 0.05 & 0.036 & 2.00 & 90 & 36.0 \\
\hline HAac-1 & 0 & 0.05 & 2.00 & 90 & 33.5 \\
\hline
\end{tabular}

a $70^{\circ} \mathrm{C}$; methanol was used as the solvent unless otherwise listed; [AIBN], 1/400 of total monomer concentration.

b methanol containg $25-\mathrm{vol} \%$ water, BPO as initiator.

c methanol containg 25-vol \% tetrahydrofuran.

d [AIBN], 1/500 of total monomer concentration. 


\section{S. Shinkai and T. Kunitake}

pressed below $4 \mathrm{~mol} \%$, in order to make clear the effect of the composition of the A unit.

\section{Characterization of Polymers}

The contents of PI, BA, NP, and HA units were determined by titration at $30^{\circ} \mathrm{C}$ in $1.0-M$ aqueous $\mathrm{KCl}$. The Visible absorption spectra of NP units and elemental analysis were also useful for this purpose. The polymer compositions were determined, as shown in Table III, by a combination of these techniques.

Some properties of the polymer catalysts are also listed in Table III. The modified Henderson-

Table III. Properties of polymer catalysts

\begin{tabular}{|c|c|c|c|c|c|}
\hline \multirow{2}{*}{ Polymer } & \multirow{2}{*}{$\begin{array}{l}\text { PI unit, }{ }^{\mathrm{d}} \\
\text { mol } \%\end{array}$} & \multirow{2}{*}{$\begin{array}{c}\text { A unit, }{ }^{\mathrm{d}} \\
\text { mol } \%\end{array}$} & \multicolumn{2}{|c|}{$\mathrm{p} K_{\mathrm{a}}$} & \multirow{2}{*}{$\begin{array}{c}n^{\prime} \text { of } \\
\text { PI }\end{array}$} \\
\hline & & & PI & A & \\
\hline \multicolumn{6}{|c|}{$\mathbf{A}=\mathbf{B S}$} \\
\hline PI-BS-1 & 3.5 & 4.1 & 5.80 & - & 1.16 \\
\hline PI-BS-2 & 3.5 & 26.0 & 5.82 & - & 1.39 \\
\hline PI-BS-3 & 3.4 & 54.9 & 5.89 & - & 1.49 \\
\hline PI-BS-4 & 3.5 & 71.0 & 6.09 & - & 1.20 \\
\hline PI-BS-5 & 3.7 & 96.3 & 6.44 & - & 1.04 \\
\hline \multicolumn{6}{|c|}{$\mathbf{A}=\mathbf{B} \mathbf{A}$} \\
\hline PI-BA-1 & 2.1 & 2.1 & 5.78 & 4.03 & 1.11 \\
\hline PI-BA-2 & 2.2 & 14.5 & 5.97 & 4.27 & - \\
\hline PI-BA-3 & 2.2 & 33.1 & - & - & - \\
\hline PI-BA-4 & 2.5 & 51.0 & - & - & - \\
\hline PI-BA-5 & 2.9 & 97.1 & - & - & - \\
\hline \multicolumn{6}{|c|}{$A=N P$} \\
\hline PI-NP-1 & 1.3 & 4.1 & - & - & - \\
\hline $\mathrm{PI}-\mathrm{NP}-2^{\mathrm{a}}$ & 1.6 & 7.9 & - & - & - \\
\hline $\mathrm{PI}-\mathrm{NP}-3^{\mathrm{b}}$ & 2.7 & 9.2 & - & - & - \\
\hline NP-1 & 0 & 3.8 & - & 6.52 & - \\
\hline \multicolumn{6}{|c|}{$\mathrm{A}=\mathrm{NPac}$} \\
\hline $\mathrm{PI}-\mathrm{NPac}$ & 2.7 & 9.2 & - & - & - \\
\hline NPac-1 & 0 & 9.6 & - & - & - \\
\hline \multicolumn{6}{|c|}{$\mathrm{A}=\mathrm{HA}$} \\
\hline $\mathrm{PI}-\mathrm{HA}^{\mathrm{c}}$ & 2.2 & 1.7 & 5.87 & 8.98 & 1.29 \\
\hline HA-1 & 0 & 2.8 & - & 8.80 & - \\
\hline
\end{tabular}

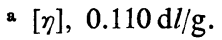

b Hydrolysis product of PI-NPac; [ $\eta], 0.191 \mathrm{~d} l / \mathrm{g}$.

- Hydrolysis products of PI-HAac and HAac-1, respectively.

d The compositions of terpolymers were evaluated by two independent results as follows: PI-BS$1-5$, titration of PI and elemental analysis; PIBA-3-5, titration of PI+BA and elemental analysis; PI-NP-1 -3 , titration of $\mathrm{PI}+\mathrm{NP}$ and visible absorption of NP; PI-HA, PI-BA-1-2 titration (titration curves for each functional group were separated).
Hasselbach equation was applied to the titration curve, in which $(1-\alpha)$ represents the degree of protonation of the dissociable functions, and $n^{\prime}$, if greater than unity, indicates the presence of electrostatic repulsion between the protonated phenylimidazole units.

$$
\mathrm{p} K_{\mathrm{a}}=\mathrm{pH}+n^{\prime} \log [(1-\alpha) / \alpha]
$$

Viscosities of the polymer catalysts were measured at $30^{\circ} \mathrm{C}$ by using a modified Ubbelohde viscometer. Linear plots of $\eta_{\mathrm{sp}} / C$ vs. $C$ were observed for all the polymer samples in $1.0-M$ $\mathrm{KCl}$, which was the same condition as that of the kinetic measurement. It is seen, therefore, that the high ionic strength employed here is sufficient to suppress the electroviscous effect.

\section{Kinetics}

The catalytic hydrolysis was carried out by using a pH-stat system (TOA Electronics Ltd., model HS-1B) mainly at pH 8.0 and $30^{\circ} \mathrm{C}$ in $0.1-M$ aqueous $\mathrm{KCl}$. The observed rate $\left(v_{\text {obs }}\right)$ is the sum of the spontaneous rate $\left(v_{\mathrm{sp}}\right)$ and the catalytic rate $\left(v_{\text {cat }}\right)$. The details of the procedure for determination of $v_{\text {cat }}$ values have been described previously. ${ }^{1}$

The hydrolysis of NPac unit in polymer was conducted in aqueous solutions buffered by Tris $(0.02 \mathrm{M})$ at $28^{\circ} \mathrm{C}$. The ionic strength was adjusted to 0.1 with $\mathrm{KCl}$. The hydrolysis rates were determined by monitoring the absorption of nitrophenolate unit $\left(\lambda_{\max } 432 \mathrm{~nm}, \log \varepsilon=3.58\right.$, as determined by using NP-1 polymer).

\section{RESULTS}

\section{Catalytic Hydrolysis with $P I-B S$ and $P I-B A$ Terpolymers}

The catalytic hydrolysis of $\mathrm{ANTI}^{+}$and $\mathrm{ABA}^{-}$ with PI-BS and PI-BA terpolymer catalysts proceeded according to Michaelis-Menten kinetics (eq 2), in which the reaction rate reaches a saturation value $\left(v_{\max }=k_{\mathrm{cat}}[\mathrm{C}]\right)$ at high substrate concentrations. The reaction parameters, $k_{\text {cat }}$ and $K_{\mathrm{m}}$, were calculated from the linear relationship in the Lineweaver-Burk plot (eq 4):

$$
\frac{1}{v_{\text {cat }}}=\frac{K_{\mathrm{m}}}{k_{\text {cat }}[\mathrm{C}]} \cdot \frac{1}{[\mathrm{~S}]}+\frac{1}{k_{\text {cat }}[\mathrm{C}]}
$$

where [C] denotes the concentration of unprotonated imidazole. The results were sum- 
Table IV. Catalytic hydrolysis by the phenylimidazole function in the terpolymers ${ }^{a}$

\begin{tabular}{|c|c|c|c|c|c|}
\hline \multirow{2}{*}{ Polymer } & \multirow{2}{*}{$\begin{array}{c}\text { A } \\
\text { unit, } \\
\text { mol } \%\end{array}$} & \multicolumn{2}{|c|}{$\begin{array}{c}\text { Substrate }= \\
\text { ANTI }^{+}\end{array}$} & \multicolumn{2}{|c|}{$\begin{array}{c}\text { Substrate }= \\
\text { ABA }^{-}\end{array}$} \\
\hline & & $\begin{array}{l}k_{\text {cat }} \times 10^{3}, \\
\min ^{-1}\end{array}$ & $\begin{array}{l}K_{\mathrm{m}} \\
\mathrm{m} M\end{array}$ & $\begin{array}{c}k_{\text {cat }} \times 10^{3} \text {, } \\
\min ^{-1}\end{array}$ & $\begin{array}{l}K_{\mathrm{m}} \\
\mathrm{m} M\end{array}$ \\
\hline PI-BS-1 & 4.1 & 16.4 & 21 & 4.2 & 8.7 \\
\hline PI-BS-2 & 26.0 & 20.5 & 30 & 5.0 & 9.3 \\
\hline $\mathrm{PI}-\mathrm{BS}-3$ & 54.9 & 38.3 & 32 & 14 & 17.5 \\
\hline PI-BS-4 & 71.0 & 38 & 24 & 19 & 19 \\
\hline PI-BS-5 & 96.3 & 43 & 14.5 & 22 & 26 \\
\hline PI-BA-1 & 2.1 & 41 & 83 & & \\
\hline PI-BA-2 & 214.5 & 51 & 83 & 11.9 & 19 \\
\hline PI-BA-3 & 33.1 & 74 & 38 & 25.7 & 17 \\
\hline PI-BA-4 & 51.0 & 53 & 25 & 13.1 & 50 \\
\hline PI-BA-5 & b 97.1 & 48 & 18 & 10.5 & 55 \\
\hline PI-NP-1 & 4.1 & 92 & 143 & & \\
\hline PI-NP-2 & 7.9 & 109 & 200 & 13.6 & 14 \\
\hline PI-NP-3 & 9.2 & 95 & 41 & 18 & 20 \\
\hline PI-HA & 1.7 & $33^{c}$ & 56 & & \\
\hline
\end{tabular}

a $30^{\circ} \mathrm{C}$; $1.0-\mathrm{M} \mathrm{KCl}$; pH 8.0; [PI unit], 0.52-1.71× $10^{-3} \mathrm{M}$; [Substrate], 0.005-0.10M.

b 4 -vol $\%$ acetonitrile.

c $k_{\text {cat }}$ for the PI unit; $k_{\text {cat }}$ for the HA unit was $870 \mathrm{~min}^{-1}$.

marized in Table IV. The $K_{\mathrm{m}}$ value for $\mathrm{ANTI}^{+}$ decreased with increase in the content of BS and BA units in polymers. In contrast, the valve of $K_{\mathrm{m}}$ for $\mathrm{ABA}^{-}$tripled during the same increase. It is evident, therefore, that $\mathrm{ANTI}^{+}$, the cationic substrate, is favorably bound to the anionic polymer catalysts, and that the electrostatic interaction contributes to the formation of C.S complex in addition to the hydrophobic interaction.

\section{Hydrolysis of NPac Unit}

In order to assess the catalytic activity of the intrapolymeric PI unit toward the o-nitrophenyl ester unit(NPac), hydrolysis was conducted in three different manners: (A) spontaneous hydrolysis of the NPac unit in the polymer (NPac1); (B) catalytic hydrolysis of the NPac unit in NPac-1 by a monomeric imidazole, AcPI; (C) catalytic hydrolysis of the NPac unit in PINPac by the intra-polymeric PI unit. The reaction rates were determined by the measurement of the absorption based on the released o-nitrophenolate anion in visible spectroscopy (Table V). The addition of AcPI slightly increased the apparent reaction rate. On the other hand, the NPac unit in the PI-NPac terpolymer decayed rapidly due to the intra-polymeric catalysis of
Table V. Hydrolysis of NPac unit in polymer ${ }^{a}$

\begin{tabular}{|c|c|c|c|c|}
\hline Method & Polymer & $\underset{M}{\text { Imidazole }}$ & $\begin{array}{l}k_{\mathrm{app}} \\
\min ^{-1}\end{array}$ & $\begin{array}{c}k_{\text {cat }},{ }^{\mathrm{b}} \\
M^{-1} \mathrm{~min}^{-1}\end{array}$ \\
\hline A & NPac-1 & - & 0.0050 & \\
\hline B & NPac-1 & $\begin{array}{r}2.90 \times 10^{-4} \\
(\mathrm{AcPI})\end{array}$ & 0.0068 & 4.8 \\
\hline $\mathrm{C}$ & $\mathrm{PI}-\mathrm{NPac}$ & $\begin{array}{r}1.46 \times 10^{-4} \\
\quad(P I \text { unit })\end{array}$ & 0.0236 & 127 \\
\hline a Tris & buffer 0.02 & M; pH 8.0; & $28.0^{\circ} \mathrm{C}$ & 0.10 wi \\
\hline
\end{tabular}

the PI unit. These results suggest the preference of the intra-polymeric catalysis to that of the intermolecular AcPI catalysis. In fact, the second-order rate constant for process $\mathrm{C}$ is 26 times faster than process $B$. Therefore, the introduction of a catalytic group into a polymeric substrate greatly improves the intramolecular catalytic efficiency.

\section{Catalytic Hydrolysis with PI-NP Terpolymers}

The catalytic hydrolysis with PI-NP terpolymer catalysts also satisfied Michaelis-Menten kinetics and showed increased $k_{\text {cat }}$ values relative to those with PI-BS and PI-BA catalysts (Table IV). Since the intra-polymeric catalysis of $o$-nitrophenyl ester unit by the PI-unit is efficient, it becomes important to assess whether the nitrophenolate function in PI-NP polymers serve as a nucleophile toward the substrates. Once the acetyl group is transferred from the substrate to the $o$-nitrophenolate unit, the acetyl intermediate would be decomposed rapidly by the intrapolymeric catalysis of phenylimidazole (Scheme I).

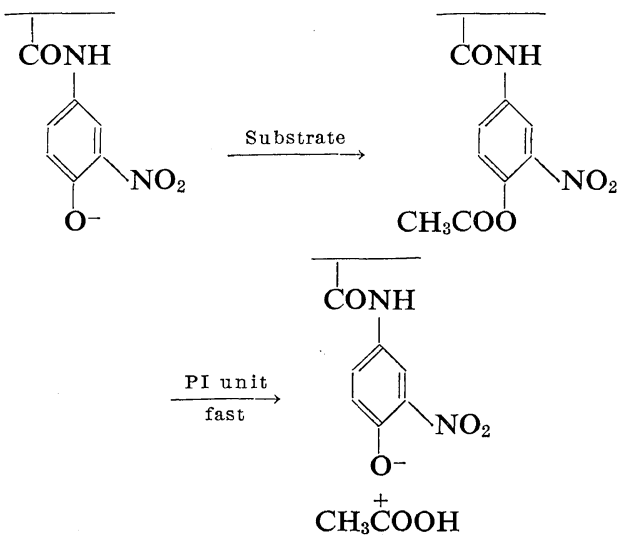

Scheme I 


\section{S. Shinkai and T. Kunitake}

The NP-1 polymer, having no PI unit, was added to an $\mathrm{ANTI}^{+}$solution ([NP unit] $=3.80 \times 10^{-4} M$, $\left.\left[\mathrm{ANTI}^{+}\right]=2.0 \times 10^{-4} \mathrm{M}, \mathrm{pH} 8.0\right)$ and then the time-course of the nitrophenolate absorption (432 $\mathrm{nm}$ ) and the alkali consumption due to the hydrolysis were examined. The absorption at $432 \mathrm{~nm}$ was constant and the rate of alkali consumption decreased by ca. $5 \%$ compared to the spontaneous rate. These observations indicate that the nitrophenolate function in the polymer does not act as a nucleophile, but rather retards the spontaneous decay of $\mathrm{ANTI}^{+}$. The $k_{\text {cat }}$ values in the catalytic hydrolysis with PI-NP polymers were larger than those with PI-BS and PI-BA polymers, so that it is concluded that the nitrophenolate function enhances the nucleophilicity of the PI group.

Catalytic Hydrolysis with Polymers Containing the Hydroxamate Function

Hydroxamate groups have been shown to display excellent nucleophilic activity due to the $\alpha$-effect. ${ }^{11-14}$ High esterolytic activities were observed for the monomeric hydroxamates ${ }^{15,16}$ as well as for the polymeric hydroxamates. ${ }^{17}$ The $N$-phenylacetohydroxamate unit in the acrylamide-base polymer (HA-1) also gave rise to rapid alkali consumption which concluded within 15 min (Figure 1). The rate of the subsequent alkali consumption was identical with that of spontaneous hydrolysis of $\mathrm{ANTI}^{+}$, suggesting that the decomposition of the acetyl hydroxamate intermediate is too slow to be discriminated from the spontaneous hydrolytic rate (Scheme

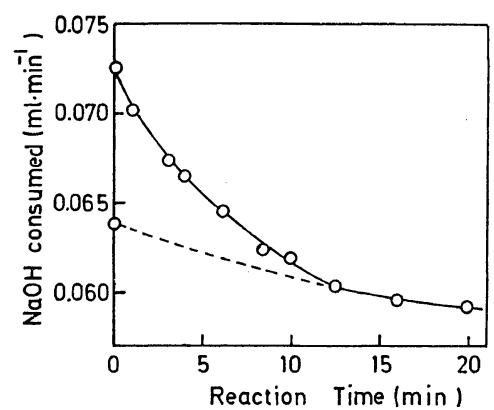

Figure 1. Hydrolysis rate of $\mathrm{ANTI}^{+}$with the hydroxamate-containing polymer (HA-1). The dotted curve denotes the spontaneous hydrolysis rate. pH $9.0 ; 30^{\circ} \mathrm{C} ; \mu, 1.0$ with $\mathrm{KCl} ;[\mathrm{S}], 0.010-M \mathrm{ANTI}^{+}$, [HA unit], $3.20 \times 10^{-3} M$; NaOH used is $0.0935 \mathrm{~N}$.
II). The apparent second-order rate constant, $k_{2}\left(=v_{\text {obs }} /\left[\right.\right.$ hydroxamate][ANTI $\left.\left.{ }^{+}\right]\right)$, was computed to be $46 M^{-1} \mathrm{~min}^{-1}$ at $30^{\circ} \mathrm{C}, 1.0-M \mathrm{KCl}$, whereas the $k_{2}$ value for the hydrolysis of $\mathrm{ANTI}^{+}$catalyzed by AcPI was $0.75 M^{-1} \mathrm{~min}^{-1}$ under the same reaction conditions.

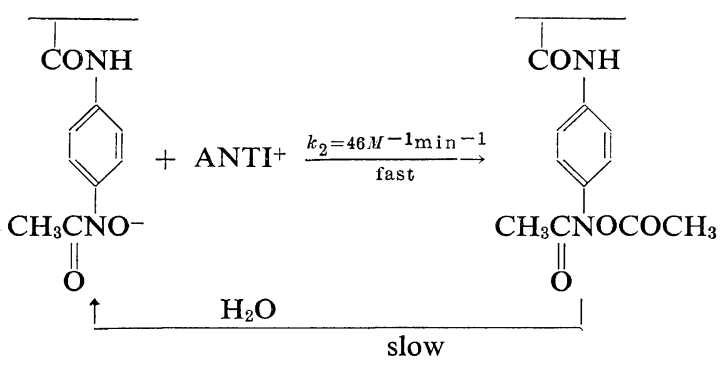

Scheme II

These results imply that the hydroxamate function in the PI-HA polymer attacks the substrate more readily than the imidazole function does.

The catalytic hydrolysis of $\mathrm{ANTI}^{+}$with $\mathrm{PI}$ HA polymer also was in accord with the Michaelis-Menten equation (eq 2). The hydrolysis was conducted at two $\mathrm{pH}$ values, 8.0 and 9.1 , where the $K_{\mathrm{m}}$ values were found to be identical. The observed rate is composed of the PI and HA terms as follows:

$$
v_{\text {cat }}=k_{\text {cat }}[\mathrm{C}]=k_{\text {cat, } \mathrm{PI}}[\mathrm{PI}]+k_{\text {cat }, \mathrm{HA}}[\mathrm{HA}]
$$

The $k_{\text {cat,PI }}$ and $k_{\text {cat,HA }}$ values were calculated to be 33 and $870 \mathrm{~min}^{-1}$, respectively, from the $\mathrm{p} K_{\mathrm{a}}$ of the HA unit and the overall rates observed.

\section{DISCUSSION}

\section{Substrate Binding}

The catalytic hydrolysis by AcPI, which corresponds to the monomeric unit of the polymeric PI residue, followed the second-order kinetics, whereas all the polymers in Table III showed saturation of the reaction rate at high substrate concentrations. It is obvious, therefore, that this difference is caused by the strengthened hydrophobic binding sites brought about by the aggregation of polymer residues. In previous publications we have also substantiated the intrapolymeric aggregation of hydrophobic pendent residues in aqueous systems through the titration, viscometric, and catalytic behavior. ${ }^{3-5}$ 


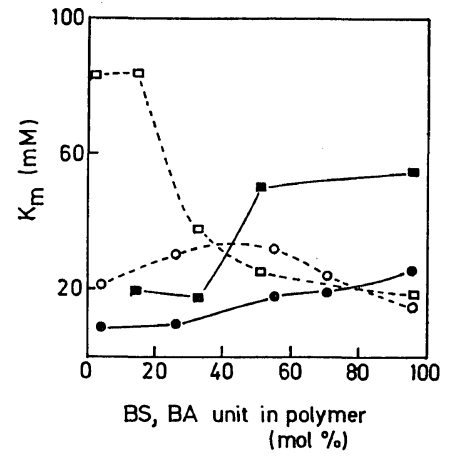

Figure 2. Variation of $K_{\mathrm{m}}$ with the degree of anionic functions: $O$, $\mathrm{ANTI}^{+}$with PI-BS polymers; $\square$, ANTI $^{+}$with $\mathrm{PI}-\mathrm{BA}$ polymers; $-\mathrm{ABA}^{-}$ with PI-BS polymers; $1 \mathrm{ABA}^{-}$with $\mathrm{PI}-\mathrm{BA}$ polymers.

The effect of the content of the second component (A unit) on the substrate binding is shown in Figure 2. One would anticipate that the anionic polymer would favor the cationic substrate in preference to the anionic counterpart, and this is the case. The increase of BA content brought forth the decrease of $K_{\mathrm{m}}$ in the binding of $\mathrm{ANTI}^{+}$and the increase in the $\mathrm{ABA}^{-}$ binding. This result means that some selectivity could be achieved by the combination of the charged polymer and substrates. On the other hand, the effect of the BS content on the $K_{\mathrm{m}}$ value is rather slight. This difference between BS- and BA-containing polymers may be caused by the conformation change, which would bring about a difference in the charge density around the PI unit.

We previously examined the esterolytic efficiency of the PI unit in the copolymers with acrylic acid and methacrylic acid. ${ }^{5}$ Interestingly, the rate of catalytic hydrolysis of $\mathrm{ABA}^{-}$with the PI-acrylic acid copolymer was proportional to the substrate concentration and the secondorder rate constant $\left(0.163 \mathrm{M}^{-1} \mathrm{~min}^{-1}\right)$ was smaller than that obtained with AcPI catalyst (0.272 $M^{-1} \min ^{-1}$ ). This smaller catalytic activity of the polymer is probably due to the repulsion between the like charges of the polymer and the substrate. In contrast, the anionic polymer of Table IV showed substrate binding for $\mathrm{ABA}^{-}$, in spite of the expected electrostatic repulsion. Observation of the Michaelis-Menten kinetics in the present system proves that the hydrophobic attraction overcomes the electrostatic repulsion in substrate binding.

\section{Intracomplex Catalysis}

It is expected in the intracomplex hydrolysis of bound substrates that the second functional groups cooperate with the PI unit to result in the enhanced catalytic efficiency. A basic functional group will be preferred for this purpose. The $\mathrm{p} K_{\mathrm{a}}$ value of sulfonic acids is estimated to be around $0.6^{18}$, and the nucleophilic and/or general-basic catalytic contribution of the BS unit appears negligible. The $\mathrm{p} K_{\mathrm{a}}$ value of the PI unit in the PI-BS terpolymer rose with increase in the BS content and $k_{\text {cat }}$ showed an apparent parallel behavior (Figure 3). One may consider that the BS unit simply provides negatively charged environments where $\mathrm{p} K_{\mathrm{a}}$ (and therefore the nucleophilicity) of the PI unit is enhanced. It is to be noted that the $n^{\prime}$ value of the PI unit in the PI-BS polymer is maximal at ca. $50-\mathrm{mol} \%$ BS content (Table III). This indicates that the electrostatic interaction of the PI unit is greatest when ca. 50-mol\% BS unit is contained. Conceivably, this effect is superimposed on the environment effect of the BS unit mentioned above.

Carboxylate groups play an important role in some hydrolytic enzymes. ${ }^{7}$ This is also true in synthetic systems, as shown clearly in the

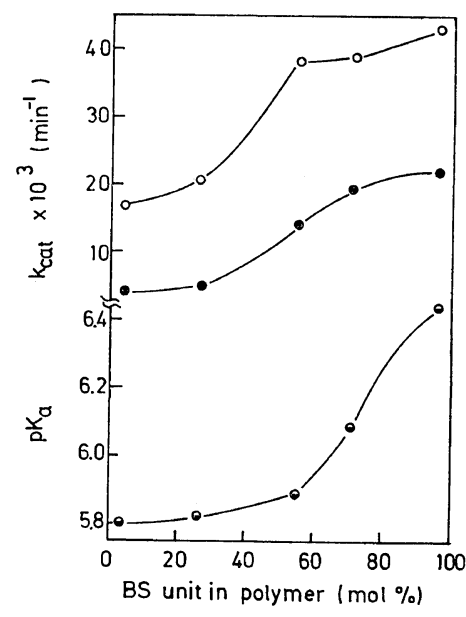

Figure 3. Variation of $k_{\text {cat }}$ with the degree of BS unit and correlation with $\mathrm{p} K_{\mathrm{a}}$ : $\bigcirc, \mathrm{ANTI}^{+}$with PI-BS polymers; - $\mathrm{ABA}^{-}$with $\mathrm{PI}-\mathrm{BS}$ polymers. 


\section{S. Shinkai and T. Kunitake}

hydrolysis of acrylic acid-nitrophenyl acetate copolymer ${ }^{19}$ and of aspirin. ${ }^{20}$ The importance of the imidazole-carboxylate combination in the polymer catalysis has been reported by Overberger, et al., ${ }^{21}$ and Shimidzu, et al., ${ }^{22}$ Overberger, et al., observed that the apparent second-order rate constant was maximal at 47mol\% imidazole content for the hydrolysis of $\mathrm{ANTI}^{+}$catalyzed by copolymers of 4(5)-vinylimidazole and acrylic acid. In contrast, the activity of the vinylimidazole-vinylsulfonic acid copolymer increased monotonously with increase in the content of the vinylsulfonic acid unit. Subsequently, Shimidzu and coworkers established that the catalytic hydrolysis by vinylimidazole-acrylic acid copolymers was of the MichaelisMenten type, and found that the intracomplex rate constant $k_{\text {cat }}$ was minimal at $20-30-\mathrm{mol} \%$ imidazole content. The maximum of the apparent rate in this region was brought about, instead, by the favorable binding.

In the present study, the plot of $k_{\text {cat }} v s$. the BA content in the PI-BA terpolymer gave a maximum at ca. 30-mol\% BA unit (Figure 4), whereas the $k_{\text {cat }}$ value for the PI-BS terpolymer increased monotonously with increase in the BS content (Figure 3). These trends are contrary to those observed in the above-mentioned system, and suggest that the PI and BA units act cooperatively in the catalytic process. Apparently, this cooperative action becomes particularly favorable at a BA content of ca. $30 \mathrm{~mol} \%$. The flexibility of the polymer chain, which is con-

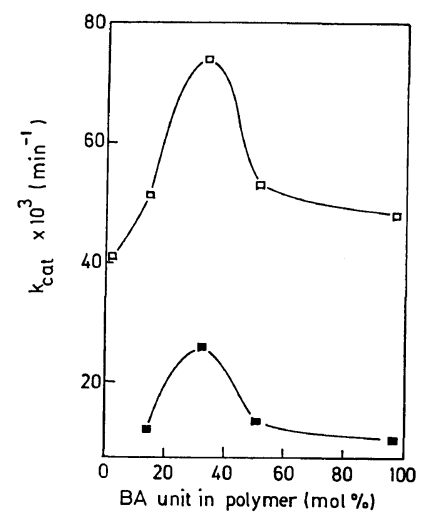

Figure 4. Variation of $k_{\text {cat }}$ with the degree of $\mathrm{BA}$ unit: $\square, \mathrm{ANTI}^{+}$with $\mathrm{PI}-\mathrm{BA}$ polymers; $\mathbf{}, \mathrm{ABA}^{-}$ with PI-BA polymers. trolled by the electrostatic repulsion and the hydrophobic attraction of side chains, can have a dominating influence on the cooperativity.

In the catalytic hydrolysis with the PI-NP polymer, we could not obtain any evidence for the nitrophenolate anion acting as a nucleophile. Therefore, the higher activity of the PI-NP polymer (ca. 2 times as reactive as PI-BA) should be attributed to the general-basic contribution of the nitrophenolate anion, which can be efficient due to its high $\mathrm{p} K_{\mathrm{a}}$ value. Unfortunately, the values of $\mathrm{p} K_{\mathrm{a}}$ for the PI unit in PI-BA and PI-NP polymers could not be determined because of the overlapping of their titration curves with those of the BA and NP groups. Therefore, the possible enhancement of catalysis due to increased $\mathrm{p} K_{\mathrm{a}}$ (i.e., nucleophilicity) of the PI unit cannot be separated from the general-basic contribution of the second functional groups.

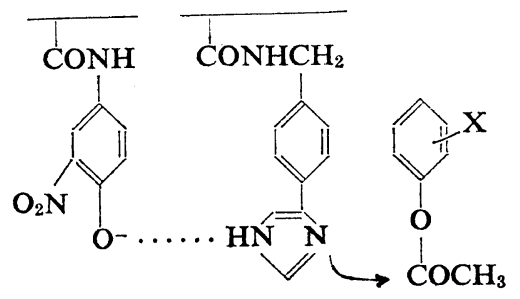

The plots of $\log k_{\text {cat }}$ of $\mathrm{A}$ unit give good linear relationships for copolymers containing less than $30 \mathrm{~mol} \%$ of A unit (Figure 5). The observed linearity may dictate that the second functional groups (BS, BA, and NP) contribute

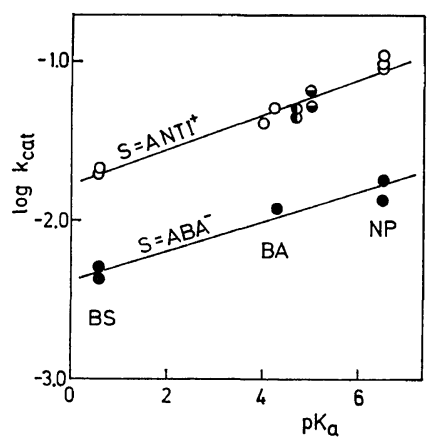

Figure 5. Relation between $\log k_{\text {cat }}$ and $\mathrm{p} K_{\mathrm{a}}$ of anionic functions. The previous results for the following systems ${ }^{5}$ are also recorded: $\mathbf{D}, \mathrm{PI}-$ acrylic acid copolymers; $\Theta$, PI-methacrylic acid copolymers. 
to the catalytic efficiency by the same mechanism (cf. eq 6).

The catalytic behavior of the PI-HA polymer is greatly different from that of other polymers. The $k_{\text {cat }}$ values of PI and HA units were determined to be 33 and $870 \mathrm{~min}^{-1}$, respectively, from the $\mathrm{pH}$ dependence of the overall $k_{\text {cat }}$ value. Since $k_{\text {eat }}$ for the HA unit is much greater than that of the PI unit, the hydrolysis may be preferentially catalyzed by the HA unit at the initial stage of the reaction. As established for PI-NPac polymer, the intra-polymeric acetyl transfer from nitrophenolate ester to imidazole is efficient. Since the alkaline hydrolysis of acetohydroxamate ester proceeds more easily than that of $p$-nitrophenyl ester, ${ }^{24}$ the ester of the HA unit would be also decomposed readily by the PI unit. Application of this scheme to the PI-HA polymer enables us to depict a novel scheme of the bifunctional catalysis (Scheme III):

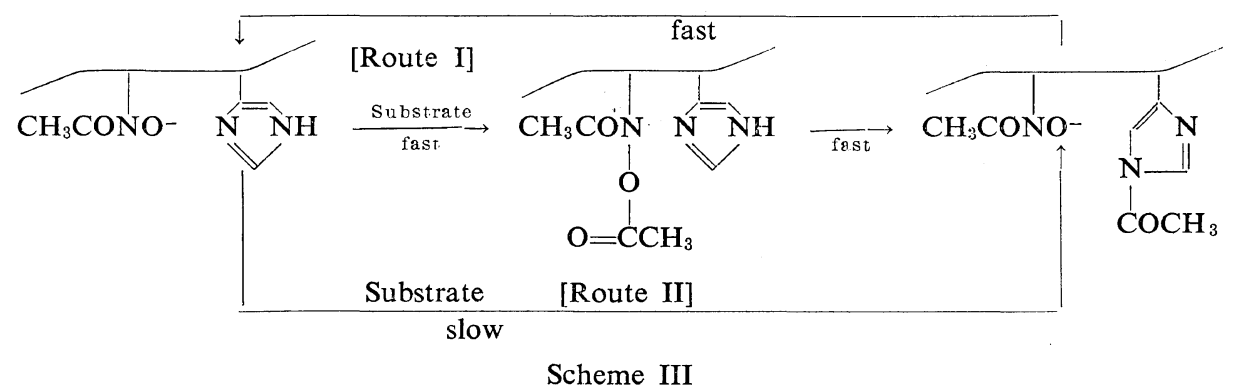

Although the deacylation of acetylimidazole is very fast, the nucleophilicity of the imidazole group is not so excellent (Route II). The hydroxamate anion shows contrasting behavior in the acylation-deacylation relationship (Scheme II). ${ }^{23,24}$ Hence, the combination of these two groups would cancel out the slower rate determining steps unless the intra-molecular acyl transfer, newly required for Route I, becomes rate-determining. One should note that the process of Route $\mathrm{I}$ is quite similar to the catalytic process of $\alpha$-chymotrypsin. Unfortunately, no clear evidence for the recycling of the catalyst groups shown in Route I could be obtained from the PI-HA polymer at hand, because it was difficult to discriminate the catalytic turn-over from the spontanous hydrolysis. It is expected that the polymers containing higher compositions of the hydroxamate unit would follow Route I. In fact, recent studies in this laboratory have established that this route is taken when the copolymer of 4(5)-vinylimidazole and $\mathrm{N}$-phenylacrylohydroxamic acid ${ }^{25,26}$ is employed.

\section{REFERENCES}

1. T. Kunitake, F. Shimada, and C. Aso, J. Amer. Chem. Soc., 91, 2716 (1969).
2. T. Kunitake, F. Shimada, and C. Aso, Makromol. Chem., 126, 276 (1969).

3. T. Kunitake and S. Shinkai, J. Amer. Chem. Soc., 93, 4247 (1971).

4. T. Kunitake and S. Shinkai, ibid., 93, 4256 (1971).

5. T. Kunitake and S. Shinkai, Makromol. Chem., 151, 127 (1972).

6. S. Shinkai and T. Kunitake, Polymer J., 4, 253 (1973).

7. D. M. Blow, J. J. Birktoft, and B. S. Hartley, Nature, 221, 337 (1969).

8. M. M. Koton, T. A. Sokolova and G. M. Chetyrkina, Zhur. Obshchei Khim. 27, 185 (1957); Chem. Abstr., 51, 12859 (1957).

9. M. Bodanoszky and V. Du Vigneaud, J. Amer. Chem. Soc., 81, 5688 (1959).

10. O. Kamm, Organic Synthesis, Coll. Vol. I, 445 (1956).

11. H. Kwart and H. Omura, J. Org. Chem., 34, 318 (1969).

12. J. H. Aubort and R. F. Hudson, Chem. Commun., 1970, 937 and 938.

13. M. Dessolin, Tetrahedron Lett., 1972, 4585.

14. F. Filippini and R. F. Hudson, Chem. Commun., 1972, 522.

15. W. B. Gruhn and M. L. Bender, J. Amer. Chem. Soc., 91, 5883 (1969).

16. R. Hershfield and M. L. Bender, ibid., 94, 1376 (1972). 


\section{S. Shinkai and T. Kunitake}

17. T. Kunitake, Y. Okahata, and R. Ando, Bull. Chem. Soc. Japan., 47, 1509 (1974).

18. H. E. Fierz and P. W. Weissenbach, Helv. Chim. Acta, 3, 305 (1920).

19. H. Morawetz and P. E. Zimmering, J. Phys. Chem., 58, 753 (1954).

20. A. R. Fersht and A. J. Kirby, J. Amer. Chem. Soc., 89, 4853, 4857 (1967).

21. C. G. Overberger and H. Maki, Macromolecules, 3, 214, 220 (1970).

22. T. Shimidzu, A. Furuta, and Y. Nakamoto, ibid., 7, 160 (1974).

23. T. C. Bruice and S. J. Benkovic, "Bioorganic Mechanisms," Benjamin, New York, N.Y., 1969, Chapter 2.

24. W.P. Jencks, "Catalysis in Chemistry and Enzymology,' McGraw-Hill, Inc., New York, 1969, Chapter 8.

25. T. Kunitake and Y. Okahata, Chem. Lett., 1974, 1057.

26. T. Kunitake and Y. Okahata, J. Amer. Chem. Soc., submitted. 